\title{
Differential expression of breast cancer-associated genes between stage- and age-matched tumor specimens from African- and Caucasian-American Women diagnosed with breast cancer
}

\author{
Jessica M Grunda', Adam D Steg ${ }^{2}$, Qinghua He ${ }^{3}$, Mark R Steciuk4, Suzanne Byan-Parker ${ }^{4}$,
} Martin R Johnson ${ }^{5}$ and William E Grizzle ${ }^{4^{*}}$

\begin{abstract}
Background: Recent studies suggest that the poorer breast cancer outcome observed in African-American women (AAW) may, in part, result from underlying molecular factors. The purpose of this study was to investigate gene expression differences between Caucasian-American women (CAW) and AAW that may contribute to this poorer prognosis.

Methods: The expression of 84 genes involved in breast carcinoma prognosis, response to therapy, estrogen signaling, and tumor aggressiveness was assessed in age- and stage-matched CAW and AAW paraffin-embedded breast cancer specimens. The Wilcoxon-Mann-Whitney Test was used to identify genes with a significant difference in expression between CAW and AAW. To determine if the differentially expressed genes could segregate between the CAW and AAW, we performed semi-supervised principal component analysis (SSPCA).

Results: Twenty genes were differentially expressed between AAW and CAW. SSPCA incorporating these 20 genes segregated AAW and CAW into two distinct groups. AAW were significantly $(p<0.05)$ more likely to display aberrations in $G_{1} / S$ cell-cycle regulatory genes, decreased expression of cell-adhesion genes, and low to no expression of ESR1, PGR, ERBB2 and estrogen pathway targets.

Conclusions: The gene expression differences identified between AAW and CAW may contribute to more aggressive disease, resistance to therapy, enhanced metastatic potential and poor clinical outcome. These findings support the hypothesis that breast cancer specimens collected from AAW display distinct gene expression differences compared to similar tissues obtained from CAW. Additional population-based studies are necessary to determine if these gene expression variations contribute to the highly aggressive and treatment-resistant breast cancer phenotype frequently observed in AAW.
\end{abstract}

Keywords: Breast cancer, Gene expression, Race, Estrogen signaling, Cell cycle, Cell migration

\footnotetext{
*Correspondence: wgrizzle@uab.edu

${ }^{4}$ Department of Pathology, University of Alabama at Birmingham, Zeigler Research Building, 703 South 19th Street, ZRB 408, Birmingham, AL 35294, USA

Full list of author information is available at the end of the article
} 


\section{Background}

Multiple studies have found distinct ethnic disparities in breast cancer outcome between African-American women (AAW) and Caucasian-American women (CAW) in incidence rate, age-of-onset, mortality and survival. Although the overall incidence rate for breast cancer is higher in CAW compared to AAW, the ageadjusted mortality rate for AAW $(33 / 100,000)$ is significantly higher than any other ethnic group examined, including women of Caucasian descent [1]. In fact, AAW at all breast cancer stages assessed (localized, regional \& distant) have a much lower 5-year survival rate (78\%) compared to CAW (90\%) [2]. Although breast cancer risk increases with age in all ethnicities, women of African-American ancestry are more often diagnosed at a much younger age, with $30-40 \%$ of AAW diagnosed with breast cancer prior to 50 years of age, compared to just $20 \%$ for CAW [3]. This trend is even more striking considering AAW are diagnosed more frequently with higher-grade tumors that are resistant to traditional therapies [4]. The mechanisms underlying poorer outcome in AAW diagnosed with breast cancer remains to be elucidated.

Early studies suggested that the poorer outcome observed for AAW diagnosed with breast cancer resulted from disparities in social economic status (SES), education level, access to health care, diet, religious beliefs, and geographical location [5-9]. However, recent research suggests that differences in clinical outcomes likely arise from both societal and genetic factors. Several large population-based meta-analyses report that AAW display a significantly higher mortality rate than when compared to any other ethnicity, even after accounting for SES $[10,11]$. Additionally, even when African and Caucasian-American women had equal access to health care and/or underwent identical treatment regimens, the disparity in patient outcome persisted. For instance, two Department of Defense studies examining treatment outcome in breast cancer patients found that mortality rates were still significantly higher in AAW versus CAW even though patients had equal access to health care and underwent identical treatment regimens $[12,13]$. Another study by Albain et al. investigating survival of breast cancer patients enrolled in randomized clinical trials of the Southwest Oncology Group found that overall survival rates for African American patients were significantly poorer, even though patients received the same treatment regimens and were controlled for both prognostic factors and SES [14]. These studies collectively support the hypothesis that while there are sociological factors contributing to the higher mortality rates seen in AAW, other causative factors exist.

A mounting body of evidence now suggests that women of African-American ancestry may harbor a greater genetic predisposition for a more aggressive breast cancer phenotype. Recent studies have demonstrated that young, premenopausal women of African American descent are more likely to display histological characteristics depictive of the basal-like subtype of breast cancer, known for its aggressive behavior and poorer clinical outcome, compared to any other age group of any other ethnic background examined $[15,16]$. Histologically, breast carcinomas from AAW more often display pushing, non-infiltrative tumor margins, nuclear pleomorphism, lymphocytic infiltrate, large primary tumors, necrosis, lack of tubule formation, as well as high mitotic indices and histological grade [15,17-21]. In addition, AAW are more likely to lack expression of both the estrogen and progesterone receptors, and often display the triple negative phenotype (ER-, PR-, HER2-), thus precluding treatment with such targeted therapies as tamoxifen, anastrozole, and Herceptin [17,20,22]. Women of African-American ethinicity are also more likely to exhibit specific alterations in the levels of genes involved in cell-cycle regulation and apoptosis, including higher quantities of p16, p53, and cyclin E, and lower levels of BCL-2, cyclin D1, and p27 [20,22]. In addition to these 'basal-like' features, other studies have found that AAW had a significantly higher prevalence of deleterious mutations in BRCA1 and BRCA2 compared with CAW [23].

Many of these genetic differences may be associated with differences in tumor grade and hormone receptor status (ER and HER-2/neu), both of which have been found to independently influence gene expression profiles. Although, a study recently published by Field et al. determined that even when patient tissues were matched on age, grade, and estrogen receptor status, significant differences in gene expression profiles were still observed [24]. The genes identified spanned a diverse array of cellular functions including the proteasome system, eye lens physiology, cell growth and differentiation, and cellular immunity and inflammation [24]. While these studies collectively provided insight into potential biological factors contributing to the poor clinical outcome of AAW, further studies are needed to clarify the role of genetics in AAW breast cancer epidemiology.

The identification of potential gene expression differences driving the disparities in health outcome between AAW and CAW is critical to improving the treatment response and survival of these women as these molecular differences may impact breast cancer prevention, screening practices, diagnostic testing and treatment protocols. In this study we utilized a novel experimental approach to investigate differences in gene expression between AAW and CAW, independent from age or disease stage at diagnosis. Paraffin-embedded, age- and stage-matched breast carcinoma samples from AAW 
and CAW patients were macrodissected to enrich the specimens in tumor cell content $(>80 \%)$. Gene expression analysis of genes previously implicated in breast cancer prognosis, treatment response, estrogen signaling, and tumor aggressiveness was performed using The Human Breast Cancer and Estrogen Receptor Signaling $\mathrm{RT}^{2}$ Profiler PCR Array from SABiosciences. Using the Wilcoxon-Mann-Whitney Test we identified genes displaying a significant difference in expression between tumors obtained from AAW and CAW breast cancer patients. These analyses identified a distinct molecular profile in women of African-American descent, often associated with the basal-like phenotype and previously associated with resistance to therapy and poor clinical outcome, supporting the hypothesis that AAW may have a gene-expression based predisposition for a more aggressive disease phenotype.

\section{Methods}

\section{Selection of cases}

Consent was obtained for all patients prior to start of study. The use of human tissues was approved by and conducted in accordance with the policies of the Institutional Review Board at the University of Alabama at Birmingham. The records of archival cases of breast cancer from UAB Surgical Pathology were searched to identify age ( \pm 5 years) and stage (assessed by a pathologist) matched cases of ductal carcinoma. The quality of the available archival blocks from the matched cases was then assessed through hematoxylin and eosin $(\mathrm{H}+\mathrm{E})$ staining of newly cut sections from the original diagnostic blocks. Sections were examined and selected for areas of tumor that could be macrodissected into greater than $80 \%$ invasive cancer.

\section{Analysis of receptor status}

ER, PR and HER2 status were determined in the CAP/ CLIA accredited laboratory of University of Alabama at Birmingham Hospital with the exception of one case. Immunostaining of ER (Clone SP1) and PR (1 E2) was performed using a semi-automated immunostainer (Ventana, Model XT) and an Ultraview HPR Multitimer approach. Tumors were considered positive if $1 \%$ or greater of tumor cells stained. Percentage of staining as well as intensity $1+$ (weak) to $3+$ (strong) was also reported. The HER2/neu status was determined by CISH using the Spot-Light Kit (Invitrogen), which is specific for the HER2 gene locus on chromosome 17q11.2-21. A minimum of 30 tumor cell nuclei were evaluated per patient. Criteria are as follows: $\geq 6$ dots in the majority of carcinoma cells is amplified, 4-6 is equivocal, and $\leq 4$ dots is non-amplified. All evaluations are done by standard microscopy. Cases prior to 2005 were evaluated by immunohistochemistry where 0 was negative if no staining or membrane staining in less than $10 \%$ of tumor cells, $1+$ was negative if weak membrane staining in greater that $10 \%$ of tumor cells, $2+$ was positive if weak to moderate complete membrane staining in greater than $10 \%$ of tumor cells, and $3+$ was positive if strong complete membrane staining in greater than $10 \%$ of tumor cells $[25,26]$.

For the one case in which ER, PR, HER2/neu clinical data was unavailable, immunostaining was performed in Dr. William Grizzle's research laboratory using ER alpha (clone SP1), PR alpha and beta (clone PgR 636), and HER2/neu (clone 3B5) and evaluated by a pathologist.

\section{Sample preparation Macrodissection}

An $\mathrm{H}+\mathrm{E}$ section was matched and orientated to the paraffin block from which it was cut and areas of benign tissue and non-invasive neoplasms were identified and removed so that after macrodissection, the ductal carcinoma remaining in the block contained at least $80 \%$ ductal carcinoma. The tumor areas were re-embedded and new $\mathrm{H}+\mathrm{E}$ sections were cut to confirm that the ductal carcinoma was successfully enriched by the macrodissection. Ten 10- $\mu \mathrm{m}$ sections were then cut for RNA extraction.

\section{RNA extraction}

Paraffin tissue curls were deparaffinized as previously described [27]. Total RNA isolation was then performed using the Roche High Pure RNA Paraffin Kit (Roche Diagnostics, Manheim, Germany) as per manufacturer's instructions. Total RNA was eluted in $30 \mu \mathrm{l}$ of RNasefree water and stored at $-80^{\circ} \mathrm{C}$ until further analysis. The concentration of all RNA samples was quantitated through linear regression analysis of a standard curve derived from known concentrations of normal breast RNA. Ribosomal protein, large, PO (RPLPO), which has been previously validated by our laboratory [28], was used as the housekeeping gene.

\section{Reverse transcription}

Complementary DNA was prepared using the $\mathrm{RT}^{2}$ First Strand Kit (SABiosciences, Frederick, MD) as per manufacturer's instructions. Approximately $0.5 \mu \mathrm{g}$ of total RNA from each sample was used for cDNA synthesis.

\section{Analysis of samples by the $\mathrm{RT}^{2}$ profiler $\mathrm{PCR}$ array}

The pre-designed Human Breast Cancer and Estrogen Receptor Signaling $\mathrm{RT}^{2}$ Profiler PCR Array (SABiosciences) was utilized to simultaneously analyze 84 genes related to breast cancer regulation and estrogen receptor-dependent signal transduction in cDNA samples. The housekeeping genes B2M, HPRT1, RPL13A, $G A P D H$ and $A C T B$ are included on each Array. Each 
cDNA sample was added to $2 \mathrm{X}$ SuperArray $\mathrm{RT}^{2} \mathrm{qPCR}$ Master Mix (SABiosciences) and $25 \mu \mathrm{l}$ of the mixture was added to each well of the PCR Array using an eightchannel pipettor. The plate was sealed and PCR amplification was performed using an Applied Biosystems Prism $7900 \mathrm{HT}$ sequence detection system. Thermal cycler conditions were as follows: 2 minutes at $50^{\circ} \mathrm{C}, 10$ minutes at $94.5^{\circ} \mathrm{C}$, then 40 cycles of 30 seconds at $97^{\circ} \mathrm{C}$ and 1 minute at $59.7^{\circ} \mathrm{C}$. Delta cycle threshold (Delta $\mathrm{C}_{\mathrm{T}}$ ) and expression values were calculated using the comparative cycle threshold $\left(\mathrm{C}_{\mathrm{T}}\right)$ method as previously described by our laboratory $[27,29]$.

\section{Statistical analysis}

\section{Fisher's exact test}

Fisher's exact test is a statistical significance test used in the analysis of contingency tables to calculate whether there is a significant association between categorical variables. It is employed when sample sizes are small so the normal approximation and chi-square calculations are not accurate [30].

\section{Wilcoxon-Mann-Whitney test}

In order to determine what genes were differentially expressed between the CAW and AAW, we utilized the Wilcoxon-Mann-Whitney test [31] using gene $\Delta C_{T}$ values. The Wilcoxon-Mann-Whitney test examines the null hypothesis that gene expression levels in the two groups (CAW and AAW) are independent samples from identical continuous distributions with equal medians, compared against the alternative that they do not have equal medians. Each gene is evaluated independently to determine the statistical significance of the difference between the two-group medians. A p-value of $<0.05$ was considered statistically significance in this study.

\section{Semi-Supervised Principal Component Analysis (SSPCA)}

To determine if the genes identified through the Wilcoxon-Mann-Whitney test could visually segregate the AAW and CAW into two distinct groups we performed SSPCA [32,33]. In traditional PCA, all gene expression values are used to identify combinations of genes that separate samples into distinct groups. SSPCA has the advantage of using only those genes previously associated with clinical and/or demographic factors, and, in this case, patient ethnicity, to segregate samples into subgroups, thus allowing clear visualization of how gene expression patterns segregate groups without interfering background noise from genes that are not differentially expressed. The Komogorov-Smirnov normality test was applied to the identified principle components (PCs) to ensure the data was approximately normally distributed [34].

\section{Pearson correlation}

To calculate the strength and direction of the linear association between the expression of gene pairs across all samples, and/or the AAW and CAW patient subpopulations individually, we used Pearson's Correlation. Pearson's correlation assumes a Gaussian distribution of gene expression values within sample sets (i.e. AAW patients).

\section{Hotelling's $T^{2}$ test}

Hotelling's $\mathrm{T}^{2}$ test is used in multivariate hypothesis testing, which is a generalization of Student's $t$ test in univariate hypothesis testing [35]. Given the case of pvariate observations from two multivariate normallydistributed populations with common covariance matrix, Hotelling's $\mathrm{T}^{2}$ statistic can be used to test the equality of the vector of means associated with the two samples [35]. In this work, we apply Hotelling's $\mathrm{T}^{2}$ test to examine the multivariate gene differences between AAW and CAW patients.

\section{Results}

\section{Patient characteristics}

Both age and disease stage at diagnosis are potential factors influencing the poorer outcome observed in women of African-American descent. To ensure that any gene expression differences identified in this study were not due to age or disease stage, we selected age- and stage-matched paraffin-embedded samples of ductal breast carcinoma samples from African- and Caucasian-American women using archival records stored at the University of Alabama at Birmingham. From 80 matched archival specimens surveyed, 12 pairs were deemed of high enough quality for macrodissection and future study. All samples examined in this study were collected through biopsy or tumor

Table 1 Unmatched characteristics in the study population

\begin{tabular}{clccc}
\hline Characteristic & AAW $(\mathbf{n}=\mathbf{1 1})$ & \multicolumn{2}{l}{ CAW $(\mathbf{n}=\mathbf{1 1})$} \\
\hline Receptor Status & & & & \\
ER & 6 & $55 \%$ & 10 & $91 \%$ \\
PR & 5 & $45 \%$ & 7 & $64 \%$ \\
HER2 & 5 & $45 \%$ & 7 & $64 \%$ \\
Tumor grade & & & & \\
Well & 0 & $0 \%$ & 2 & $18 \%$ \\
Moderate & 2 & $18 \%$ & 7 & $64 \%$ \\
Poor & 9 & $82 \%$ & 2 & $18 \%$ \\
Bloom and Richardson Score & & & & \\
I & 0 & $0 \%$ & 2 & $18 \%$ \\
II & 2 & $18 \%$ & 7 & $64 \%$ \\
III & 9 & $82 \%$ & 2 & $18 \%$ \\
\hline
\end{tabular}


Table 2 Human breast cancer and extrogen recptor RT2 profiler PCR array

\begin{tabular}{|c|c|}
\hline Description & Accession \#: \\
\hline \multicolumn{2}{|l|}{ Genes Associated with Breast Cancer Prognosis } \\
\hline Androgen receptor (AR) & NM_000044 \\
\hline $\begin{array}{l}\text { Antigen identified by monoclonal antibody } \\
\text { Ki-67 (MKI67) }\end{array}$ & NM_002417 \\
\hline B-cell CLL/lymphoma 2 (BCL2) & NM_000633 \\
\hline BCL2-associated agonist of cell death (BAD) & NM_004322 \\
\hline BCL2-associated athanogene (BAG1) & NM_004323 \\
\hline Cadherin 1, type 1, E-cadherin (CDH1) & NM_004360 \\
\hline \multicolumn{2}{|c|}{ Catenin (cadherin-associated protein), beta 1, (CTNNB1) NM_001904 } \\
\hline Cathepsin B (CTSB) & NM_001908 \\
\hline Clusterin (CLU) & NM_001831 \\
\hline Collagen, type VI, alpha 1 (COL6A1) & NM_001848 \\
\hline Cyclin A1 (CCNA1) & NM_003914 \\
\hline Cyclin A2 (CCNA2) & NM_001237 \\
\hline Cyclin D1 (CCND1) & NM_053056 \\
\hline Cyclin E1 (CCNE1) & NM_001238 \\
\hline Cyclin-dependent kinase inhibitor 1A (CDKN1A) & NM_000389 \\
\hline Cyclin-dependent kinase inhibitor 1B (CDKN1B) & NM_004064 \\
\hline Cyclin-dependent kinase inhibitor 2A (CDKN2A) & NM_000077 \\
\hline Epidermal growth factor receptor (EGFR) & NM_005228 \\
\hline Estrogen receptor 1 (ESR1) & NM_000125 \\
\hline Estrogen receptor 2 (ESR2) & NM_001437 \\
\hline Fas ligand (TNF superfamily, member 6) (FASLG) & NM_000639 \\
\hline FOS-like antigen 1 (FOSL1) & NM_005438 \\
\hline GATA binding protein 3 (GATA3) & NM_002051 \\
\hline Gelsolin (GSN) & NM_000177 \\
\hline Inhibitor of DNA binding 2 (ID2) & NM_002166 \\
\hline Insulin-like growth factor binding protein 2 (IGFBP2) & NM_000597 \\
\hline Integrin, alpha 6 (ITGA6) & NM_000210 \\
\hline Integrin, beta 4 (ITGB4) & NM_000213 \\
\hline Interleukin 2 receptor, alpha (IL2RA) & NM_000417 \\
\hline Interleukin 6 (IL6) & NM_000600 \\
\hline Interleukin 6 receptor (IL6R) & NM_000565 \\
\hline Interleukin 6 signal transducer (IL6ST) & NM_002184 \\
\hline Jun oncogene (JUN) & NM_002228 \\
\hline Kallikrein-related peptidase 5 (KLK5) & NM_012427 \\
\hline Keratin 19 (KRT19) & NM_002276 \\
\hline Kruppel-like factor 5 (KLF5) & NM_001730 \\
\hline Mitogen-activated protein kinase kinase 7 (MAP2K7) & NM_145185 \\
\hline Mucin 1, cell surface associated (MUC1) & NM_001018016 \\
\hline Nerve growth factor (NGF) & NM_002506 \\
\hline Nerve growth factor receptor (NGFR) & NM_002507 \\
\hline Prostaglandin-endoperoxide synthase 2 (PTGS2) & NM_000963 \\
\hline TNF receptor superfamily, member 6 (FAS) & NM_000043 \\
\hline
\end{tabular}

Table 2 Human breast cancer and extrogen recptor RT2 profiler PCR array (Continued)

V-erb-b2 erythroblastic leukemia viral NM_004448 oncogene homolog 2 (ERBB2)

Genes Associated with Estrogen Receptor Signaling

Non-metastatic cells 1 (NME1)

NM_000269

Phosphatase and tensin homolog (PTEN)

NM_000314

Plasminogen activator, urokinase (PLAU)

NM_002658

Progesterone receptor (PGR)

NM_000926

Serpin peptidase inhibitor, clade B, member 5 (SERPINB5)

Serpin peptidase inhibitor, clade $\mathrm{E}$, member 1 (SERPINE1)

Thrombospondin 1 (THBS1)

NM_002639

NM_000602

Topoisomerase (DNA) II alpha (TOP2A)

Transforming growth factor, alpha (TGFA)

Tumor protein p53 (TP53)

Tyrosine kinase with immunoglobulin-like and EGF-like domains 1 (TIE1)

Vascular endothelial growth factor A (VEGFA)

Genes Associated with Response to Chemotherapy

Cathepsin D (CTSD)

Complement component 3 (C3)

Heat shock $27 \mathrm{kDa}$ protein 1 (HSPB1)

Keratin 18 (KRT18)

Serpin peptidase inhibitor, member 3 (SERPINA3)

Solute carrier family 7, member 5 (SLC7A5)

Stanniocalcin 2 (STC2)

Trefoil factor 1 (TFF1)

NM_003246

NM_001067

NM_003236

NM_000546

NM_005424

NM_003376

NM_001909

NM_000064

NM_001540

NM_000224

NM_001085

NM_003486

NM_003714

NM_003225

Genes Associated with Breast Cancer

Diagnosis and Progression

BCL2-like 2 (BCL2L2)

NM_004050

CD44 molecule (CD44)

NM_000610

Claudin 7 (CLDN7)

Cytochrome P450, family 19 , subfamily A, polypeptide (CYP19A1)

Deleted in liver cancer 1 (DLC1)

NM_001307

NM_000103

NM_006094

Fibroblast growth factor 1 (FGF1)

Fibronectin leucine rich transmembrane protein 1 (FLRT1)

Gamma-aminobutyric acid (GABA) A receptor, pi (GABRP)

GNAS complex locus (GNAS)

NM_000800

NM_013280

NM_014211

NM_080425

High-mobility group box 1 (HMGB1)

NM_002128

Metallothionein 3 (MT3)

NM_005954

Nuclear transcription factor $Y$, beta (NFYB)

NM_006166

Pregnancy-associated plasma protein $\mathrm{A}$,

NM_002581 pappalysin 1 (PAPPA)

Ras-related C3 botulinum toxin substrate 2 (RAC2) 
Table 2 Human breast cancer and extrogen recptor RT2 profiler PCR array (Continued)

\begin{tabular}{ll}
\hline Ribosomal protein L27 (RPL27) & NM_000988 \\
Secretoglobin, family 1D, member 2 (SCGB1D2) & NM_006551 \\
Secretoglobin, family 2A, member 1 (SCGB2A1) & NM_002407 \\
Small proline-rich protein 1B (SPRR1B) & NM_003125 \\
Thrombospondin 2 (THBS2) & NM_003247 \\
$\begin{array}{l}\text { Tumor necrosis factor, alpha-induced protein 2 } \\
\text { (TNFAIP2) }\end{array}$ & NM_006291 \\
$\begin{array}{l}\text { V-kit Hardy-Zuckerman 4 feline sarcoma viral } \\
\text { oncogene homolog (KIT) }\end{array}$ & NM_000222 \\
Housekeeping Genes & \\
Actin, beta (ACTB) & NM_001101 \\
Beta-2-microglobulin (B2M) & NM_004048 \\
Glyceraldehyde-3-phosphate dehydrogenase (GAPDH) & NM_002046 \\
Hypoxanthine phosphoribosyltransferase 1 (HPRT1) & NM_000194 \\
Ribosomal protein L13a (RPL13A) & NM_012423 \\
\hline
\end{tabular}

resection prior to start of radiation, chemotherapy, or other therapies. Patient treatment was not significantly different between AAW and CAW for the 24 patients, and consisted mainly of lumpectomy, total mastectomy, radiotherapy, tamoxifen, and arimidex. Due to the short amount of elapsed time between initial patient diagnosis and study analysis, associations between clinical parameters (race, age, disease stage, and treatment) and patient survival could not be determined.

As illustrated in Table 1, AAW were more likely to be negative for ER, PR, and HER2, however this observation was not significant, perhaps owing to small number of samples examined in this study. In contrast, patient ethnicity was significantly associated with tumor grade $(\mathrm{p}=0.0131)$ with AAW patients more often displaying a higher tumor Grade (Table 1).

\section{Gene expression differences between AAW and CAW}

Previous studies suggested that AAW women might have a genetic predisposition for a more aggressive breast cancer phenotype. To investigate this possibility further, we examined differences between AAW and CAW patient samples in the expression of 84 genes previously implicated in breast cancer aggressiveness, estrogen receptor signaling, resistance to chemotherapy, and patient prognosis using the Human Breast Cancer and Estrogen Receptor Signaling $\mathrm{RT}^{2}$ Profiler PCR Array from SABiosciences (Table 2). Based on gene Delta $C_{T}$ values, the Wilcoxon-Mann-Whitney test determined that 20 of the 84 genes examined were significantly differentially expressed $(\mathrm{p} \leq 0.05)$ between the AAW and CAW patients, with a greater than 2-fold change in expression (Table 3; Figure 1). Of these 20 genes, only
CDKN2A displayed increased expression in women of African-American descent.

We then visualized the ability of the 20 differentially expressed genes to segregate the AAW and CAW patients into distinct molecular subgroups. SSPCA was performed by applying only the 20 genes identified by the Wilcoxon-Mann-Whitney test in principal component analysis. Application of the Kolmogorov-Smirnov normality test to the first three identified PCs determined that all three principle components (PCs) had an approximate normal distribution $(\mathrm{p}<0.05)$ across both patient ethnicities. Based on the multivariate Hotelling T-Squared test, as would be expected the 20-gene combination significantly separated the breast cancer patients into two distinct subgroups (Figure 2) using PC1 $(\mathrm{p}<0.001)$, PC1 and PC2 $(\mathrm{p}<0.001)$, or the first three PCs $(\mathrm{p}<0.001)$.

A comprehensive review of the literature determined that of the 20 differentially expressed genes, 70\% (AR, BCL2, CCND1, ESR1, GATA3, IGFBP2, IL6ST, KRT19, MUC1, PGR, SERPINE1, HSPB1, SERPINA3, and STC2) have been previously associated with estrogen signaling and/or estrogen receptor 1 expression. To determine if similar associations with estrogen signaling could be detected in this study, Pearson's correlation was used to determine the strength and direction of any underlying relationships with ESR1 expression. Of the above listed genes, ESR1 was positively associated with the expression of BCL2, GATA3, IL6ST, MUC1, SERPINE1, AR, and HSPB1 expressions in women of African-American descent, with BCL2 displaying the strongest association (Table 3). In contrast, only the expression of KRT19 and CCND1 were correlated with ESR1 expression in the Caucasian population (Table 4).

In addition to estrogen signaling genes, 4 of the 20 identified genes have been implicated in resistance to targeted therapies (ERBB2, ESR1, PGR, and AR). Previous studies have reported that tumor specimens from women of African-American heritage are significantly more likely to lack expression of the hormone receptors ESR1, PGR, and AR, compared to other ethnicities. In the current study we found significantly lower expression of these receptors (6.7-fold) in the AAW compared to CAW patients (Table 3) for PGR (58\%; 17\%), and ESR1 (58\%; 17\%) respectively. In addition, a larger percentage of AAW than CAW patients had no measurable expression of the PGR (33\%; 8\%) and ESR1 (50\%; 8\%) genes respectively. AAW patients were also less likely to express ERBB2 (42\%; 8\%).

In addition to estrogen signaling and resistance to therapy, 7 of the identified genes have been previously associated with cell cycle regulation (CCND1, CDKN1A, $C D K N 1 B$, and $C D K N 2 A)$ and breast cancer aggressiveness (CLDN7 and DLC1) (Table 3). 
Table 3 Breast cancer genes differentially expressed between CAW and AAW patient populations

\begin{tabular}{|c|c|c|c|c|c|}
\hline Gene & Description & CAW $^{\mathrm{a}}$ & AAW $^{\mathrm{b}}$ & CAW/AAW & P-valued \\
\hline \multicolumn{6}{|c|}{ Genes Associated with Breast Cancer Prognosis } \\
\hline$A R$ & Androgen receptor & 0.99 & 0.38 & 2.60 & 0.002 \\
\hline $\mathrm{BCL} 2$ & B-cell CLL/lymphoma 2 & 0.65 & 0.20 & 3.28 & 0.010 \\
\hline CCND1 & Cyclin D1 & 0.78 & 0.28 & 2.75 & 0.030 \\
\hline CDKN1A & Cyclin-dependent kinase inhibitor $1 \mathrm{~A}$ & 2.07 & 0.90 & 2.29 & 0.002 \\
\hline CDKN1B & Cyclin-dependent kinase inhibitor 1B & 1.68 & 0.74 & 2.26 & 0.001 \\
\hline CDKN2A & Cyclin-dependent kinase inhibitor $2 \mathrm{~A}$ & 1.35 & 3.55 & 0.38 & 0.046 \\
\hline ERBB2 & V-erb-b2 erythroblastic leukemia viral oncogene homolog 2 & 1.61 & 0.63 & 2.56 & 0.012 \\
\hline ESR1 & Estrogen receptor 1 & 1.79 & 0.46 & 3.91 & 0.023 \\
\hline GATA3 & GATA binding protein 3 & 1.57 & 0.17 & 9.33 & 0.001 \\
\hline IGFBP2 & Insulin-like growth factor binding protein 2, $36 \mathrm{kDa}$ & 1.53 & 0.73 & 2.11 & 0.005 \\
\hline IL6ST & Interleukin 6 signal transducer & 1.15 & 0.44 & 2.64 & 0.005 \\
\hline KRT19 & Keratin 19 & 1.44 & 0.71 & 2.03 & 0.012 \\
\hline MUC1 & Mucin 1, cell surface associated & 1.77 & 0.36 & 4.94 & 0.004 \\
\hline PGR & Progesterone receptor & 0.77 & 0.33 & 2.34 & 0.012 \\
\hline SERPINE1 & Serpin peptidase inhibitor, clade $\mathrm{E}$, member 1 & 7.59 & 3.18 & 2.38 & 0.014 \\
\hline \multicolumn{6}{|c|}{ Genes Associated with Response to Chemotherapy } \\
\hline HSPB1 & Heat shock 27 kDa protein 1 & 0.98 & 0.46 & 2.14 & 0.003 \\
\hline SERPINA3 & Serpin peptidase inhibitor, clade A, member 3 & 0.43 & 0.20 & 2.16 & 0.017 \\
\hline STC2 & Stanniocalcin 2 & 0.79 & 0.38 & 2.05 & 0.019 \\
\hline \multicolumn{6}{|c|}{ Genes Associated with Breast Cancer Progression } \\
\hline CLDN7 & Claudin 7 & 1.76 & 0.66 & 2.67 & 0.006 \\
\hline DLC1 & Deleted in liver cancer 1 & 4.27 & 0.94 & 4.52 & 0.023 \\
\hline
\end{tabular}

${ }^{a}$ Average Gene Expression of Caucasion-American Women (CAW, $n=12$ ).

${ }^{b}$ Average Gene Expression of African-Amercian Women (AAW, $n=12$ ).

c Gene Expression Fold Change Relative to the Average Gene Expression of AAW.

d P-values calculated using the Wilcoxin Rank Sum Test.

\section{Discussion}

Women of African-American descent are diagnosed with breast cancer at a younger age and clinical stage than their Caucasian counterparts. In addition, although CAW have a higher incidence of breast cancer, AAW have poorer survival rates. While multiple studies have shown that these disparities in health outcomes are, in part, due to such societal factors as social economic status, access to appropriate health care, diet and religious beliefs, population-based studies showed that differences in patient diagnosis and survival remained even after taking such factors into account, suggesting biological underpinnings in race may be responsible. Identification of genetic contributors that may be driving the racial differences in clinical outcome is critical as such factors may alter preventative medicine, cancer screening practices, and therapeutic guidelines. The aim of the current study was to gain a more in-depth understanding of gene expression differences between AAW and CAW breast cancer patients that may contribute to the poorer outcome of AAW patients.
Interestingly, even though patients were matched on both age and stage at diagnosis, tumor tissues from women of African decent were significantly more likely to be of higher grade. Although AAW tumors were also more likely to display the triple negative (ER-, PR-, HER2-) phenotype, these observations did not reach statistical significance. Higher grade and a triple negative phenotype are known negative predictors of breast cancer prognosis. Thus, these findings are in agreement with past studies and support that AAW have a molecular predisposition for a more aggressive breast cancer phenotype.

In the current study the expression of 84 genes (Table 2) previously implicated in breast cancer aggressiveness, estrogen receptor signaling, resistance to chemotherapy, and patient prognosis were examined in formalin-fixed, paraffin-embedded (FFPE) tissues obtained from age- and stage-matched AAW and CAW patients. Gene expression analysis of archival tissues has traditionally been problematic due to nucleotide degradation resulting from tissue processing. However, 


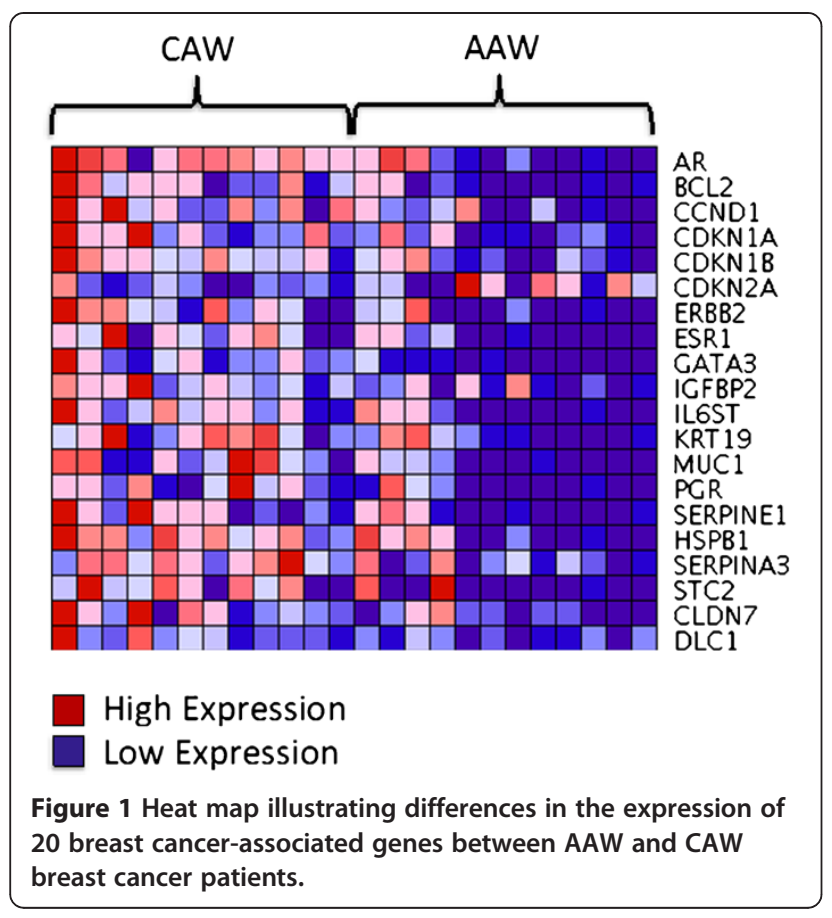

immense progress has been made in both the RNA isolation from and expression analysis of FFPE tissues $[36,37]$. In fact, several studies specifically comparing gene expression profiles from matched snap-flash frozen and FFPE tissues demonstrated significant concordance $(r=0.92, P<0.0001)[29,38]$, opening the use of archival tissues for gene expression analysis.

The current study identified 20 genes that had a significant and greater than 2-fold change in expression between AAW and CAW patients using the WilcoxonMann-Whitney test (Table 3). As illustrated in Figure 1, virtually all of the genes identified displayed increased expression in Caucasian compared to African-American women. Only CDKN1A displayed a significantly higher expression in AAW. To determine if the differential expression of these genes could discriminate between African-American and Caucasian patients, we performed SSPCA. SSPCA is advantageous over general principal component analysis in that, by only using those genes associated with ethnic background, patient clustering can be visualized without background noise resulting from genes that are not differentially expressed. This analysis determined that the AAW and CAW breast cancer patients could be visually clustered based only on the expression of these 20 genes using combinations of principal component PC1, PC2, and PC3 (Figure 2, p $<0.001$ for all $\mathrm{PC}$ combinations).

In support of previous studies examining molecular differences between African-American and CaucasianAmerican women, our study suggests that AAW have a gene expression-based predisposition for a more aggressive and treatment resistant tumor phenotype than CAW. The 20 differentially expressed genes identified (Table 3) have been implicated in cell cycle regulation, response to therapy, estrogen signaling and breast cancer aggressiveness. Abnormalities in the levels of $G_{1} / S$ phase cell-cycle regulatory proteins have been previously associated with breast cancer prognosis and response to therapy [39-44]. In our study the expression of CCND1, $C D K N 1 A$ and $C D K N 1 B$ was significantly elevated, while $C D K N 2 A$ was significantly lower, in Caucasian-American compared to African-American patients. CCND1 (Cyclin D) drives the $G_{1} / S$ phase transition through binding with cyclin dependent kinase 4 (CDK4) and cyclin dependent kinase 6 (CDK6), which then phosphorylates retinoblastoma (pRb), inducing downstream Cyclin $E$ transcription [45]. In contrast CDKN1A (p21), CDKN1B (p27), and CDKN2A (p16) are cyclin dependent kinase inhibitor proteins (CDK inhibitors) involved in cell cycle arrest through inhibition of CDK4, CDK6, and cyclin dependent kinase 2 (CDK2) [45]. As a whole, the lower expression of CCND1, CDKN1A and CDKN1B, and higher expression of $C D K N 2 A$ in AAW versus CAW patients would hypothetically result in decreased cellular proliferation in AAW tumor specimens, yet AAW patient tissues had a statistically significant higher grade than CAW specimens in this study. Interestingly, other studies have also observed this same contradiction [20], and in fact, have noted a distinct inverse relationship between cyclin D1 [20,46,47] and p16 [20,48,49] levels with poorer clinical outcome, a more aggressive cancer phenotype, and resistance to multiple chemotherapeutic agents. The collective findings of our and these studies suggest that deregulation of cell-cycle $G_{1}$ regulatory

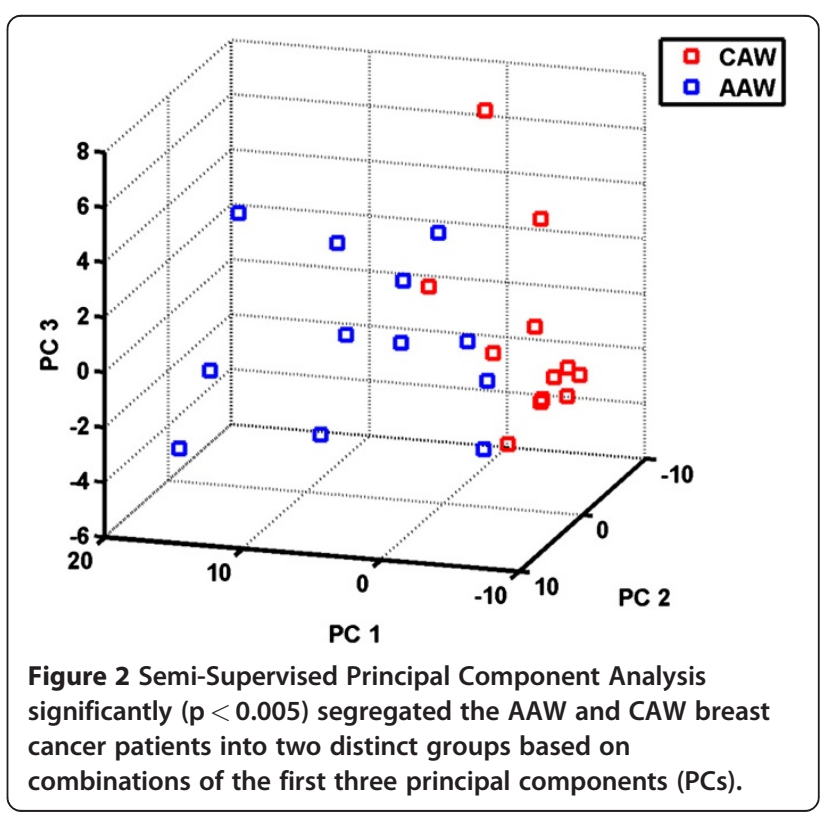


Table 4 Genes previously associated with estrogen signalling

\begin{tabular}{lccccc}
\hline & \multicolumn{2}{c}{ CAW } & & \multicolumn{2}{c}{ AAW } \\
\cline { 2 - 3 } \cline { 5 - 6 } Gene & $\mathbf{r}$ & $\mathbf{P}-$ Value & & $\mathbf{r}$ & $\mathbf{P}$ - Value \\
\hline BCL2 & NS & NS & & 0.95 & $<0.001$ \\
CCND1 & 0.65 & 0.0228 & & NS & NS \\
GATA3 & NS & NS & & 0.76 & 0.0043 \\
IGFBP2 & NS & NS & & NS & NS \\
IL6ST & NS & NS & & 0.85 & 0.0043 \\
KRT19 & 0.76 & 0.0041 & & NS & NS \\
MUC1 & NS & NS & & 0.84 & 0.0006 \\
SERPINE1 & NS & NS & & 0.86 & 0.004 \\
AR & NS & NS & & 0.80 & 0.0017 \\
HSPB1 & NS & NS & 0.82 & 0.001 \\
SERPINA3 & NS & NS & NS & NS \\
STC2 & NS & NS & NS & NS \\
\hline NSNOt Signifan & & & &
\end{tabular}

NS Not Significant.

genes is common in women of African-American heritage and may contribute to the poorer outcome of this ethnic group.

In addition to differences in cell-cycle regulatory genes, we also noted distinct differences in the expression of genes previously implicated in treatment response between AAW and CAW patient tumor specimens. As clearly illustrated in Figure 2, AAW patients had significantly lower $(\mathrm{P}<0.05)$ expression of ESR1 (ER), PGR (PR), and ERBB2 (HER-2), compared to CAW patients with a greater percentage of AAW patients exhibiting no detectable expression of ESR1 (8\% vs. 50\%) or PGR (8\% vs. $33 \%)$. A similar trend was observed in the tumoral protein receptor status for ER, PR, and HER2 (Table 1). These data add to the growing body of evidence that women of African-American descent are statistically more likely to be estrogen and progesterone receptornegative [17,50-53]. ER + and PR + tumor status is typically associated with increased survival and enhanced response to hormonal therapy. In contrast, lack of estrogen and progesterone receptor expression has been associated with a more aggressive phenotype and worse clinical outcome, as lack of estrogen or progesterone receptor status precludes treatment with tamoxifen or trastuzumab [50,51]. Unlike the racial differences observed for ESR1 and PGR, no such association has been described for ERBB2. In two separate multiethnic population-based studies conducted by Elledge et al. [52] and Porter et al. [20], HER-2 levels were found to be similar between all ethnic groups examined. However, the protein expression of HER-2 was assessed through immunohistochemistry in both of these studies, and thus differences in findings may reflect a dissociation between protein and mRNA levels of HER-2/ERRB2. While elevated ERRB2 expression has been associated with increased disease recurrence, metastasis, and shorter survival, enhanced survival is also observed for these patients when treated with HER-2 targeted therapies such as Herceptin [54,55] and Tykerb [54,56]. These results suggest AAW may harbor gene expression profile differences that increase tumor resistance to current targeted hormone and HER2 therapies. Collectively, this data supports that there are inherent gene expression differences in ESR1, PGR, and ERBB2 between women of African and Caucasian-American decent that potentially contributes to the triple negative phenotype (ER-, PR-, and HER2-) and poorer outcome often observed for AAW.

Interestingly, $70 \%$ of the genes differentially expressed between African-American and Caucasian-American women in our study have been implicated in estrogen signaling, including $A R, B C L 2, C C N D 1, E S R 1, G A T A 3$, IGFBP2, IL6ST, KRT19, MUC1, PGR, SERPINE1, HSPB1, SERPINA3, and STC2, all of which displayed decreased expression in AAW compared to CAW patients (Table 4). The expression of AR [57,58], BCL2 [57-59], CCND1 [57,58,60], GATA3 [57,58,61,62], IL6ST [57,58], MUC1 [58,63,64], PGR [57,65], SERPINE1 [66,67], HSPB1 $[58,68,69]$ and STC2 $[57,58,69,70]$ have been positively associated with ESR1 expression and/or upregulated by ESR1. Other studies have found estrogen can directly upregulate transcription of $A R$ [57], GATA3 [57], IGFBP2 [71,72], KRT19 [73], and MUC1 [64], PGR [57,74,75], SERPINE1 [76], HSPB1 [77-79], SERPINA3 [80,81], SERPINE1 [76], and STC2 [57,69,70]. In support of these studies, we also found that the expression of AR, BCL2, GATA3, IL6ST, MUC1, PGR, SERPINE1, and $H S P B 1$, were significantly associated with ESR1 expression in AAW; although, only KRT19 and CCND1 were positively correlated with ESR1 levels in American women of Caucasian descent. Interestingly, lower levels of BCL2 [59,82,83], CCND1 [46,84], GATA3 [62,85,86], IL6ST [87], KRT19 [88], MUC1 [63,64,89], PGR [65,90], SERPINE1 [66], SERPINA3 [69], STC2 [91], while higher levels of AR [65,92], SERPINA3 [69], and STC2 [69] have been associated with enhanced response to hormone therapy in sex steroid positive tumors. These results suggest that women of African-American ethnicity are more prone to displaying negative or low expression of ESR1 and its associated estrogen response genes, which have been correlated with resistance to hormone therapy and worse clinical outcome.

In addition to genes involved in cell cycle, treatment response, and estrogen signaling, we also determined that the cell adhesion-related genes CLDN7 and DLC1 were significantly decreased in the AAW patients (Table 3, Figure 1). CLDN7 is a member of the claudin family of transmembrane proteins, which are critical 
structural and molecular components of tight junctions $[93,94]$, necessary for cell-cell adhesion. Studies suggest that loss of tight junctions from down-regulation of claudins in various cancers, results in loss of cohesion, increased invasiveness, and cell dedifferentiation [95]. In support of these findings, loss or decreased expression of CLDN7, which is expressed constitutively during mammary epithelium development [96], has been significantly associated with higher histological grade, loss of cellular cohesion, and increased metastasis in breast carcinoma [97,98]. In light of this data, CLDN7 has been proposed as a breast cancer tumor-suppressor gene. Like $C L D N 7, D L C 1$ is has been considered a tumor suppressor gene involved in the regulation of the actin cytoskeleton, cell polarity, inter-cell focal adhesion, cell migration, and apoptosis [99-101] through negative regulation of Rho signaling pathways [99]. DLC1 is expressed in multiple tissues including the brain, heart, kidney, liver, lung, skin, spleen, and testis [102]. Studies have found that the mRNA levels of $D L C 1$ are diminished in various cancers [103], including breast, through loss of heterozygosity or heterozygous gene deletions [104]. Furthermore, several studies investigating the role of $D L C 1$ in breast cancer found that forced expression of $D L C-1$ in $D L C-1$ negative breast cancer cell lines resulted in growth inhibition, reduction in colony formation, and abolishment of in vivo tumorigenicity [103,105], whereas downregulation of $D L C 1$ expression enhanced cell motility and chemotactic behavior [106]. These studies suggest that loss or reduced expression of $C L D N 7$ and $D L C 1$, as was observed in tumor specimens from AAW, may lead to increased cell motility, migration, metastasis and dedifferentiation, all of which may contribute to the worse clinical prognosis observed for AAW.

The large number of gene expression differences observed in this study between AAW and CAW patients supports that women of African-American decent may harbor differences in gene expression profiles that predispose them to increased tumor grade, a triple negative (ER-, PR-, HER2-) phenotype, and worse clinical disease outcome. Future studies are needed to determine if these gene expression profiles are grade and receptor status specific or represent other attributing factors to AAW poorer prognosis.

\section{Conclusions}

The main objective of this study was to identify gene expression differences between AAW and CAW that may contribute to the poor clinical outcome observed for women of African-American descent. While the small sample size examined in this study is a limiting factor, the use of only age- and stage-matched tumor specimens strengthens findings from this study. This study demonstrated that tumor specimens from AAW were significantly more likely to display aberrations in $G_{1} / S$ cell-cycle regulatory genes, lack or exhibit low expression of ESR1, PGR, and ERBB2 with a decrease in estrogen signaling pathway targets, and display a decrease in the expression of cell-adhesion genes. These factors have been collectively linked with a more aggressive cancer phenotype, resistance to multiple chemotherapeutic agents, enhanced metastatic potential, and poorer clinical outcome, further supporting the hypothesis that women of African-American ancestry have ethnic differences in gene expression patterns that predisposes them to a highly aggressive and treatment-resistant breast cancer phenotype.

\section{Competing interests}

The authors declare that they have no competing interests.

\section{Authors' contributions}

JMG carried out the data interpretation, participated in the statistical analysis, and drafted the manuscript. ADS processed the tissue samples, carried out the gene expression analysis, and participated in drafting the manuscript. $\mathrm{QH}$ carried out the statistical analysis and participated in drafting the manuscript. MRS participated in sample acquisition. SBP participated in the study design and carried out the patient data acquisition. MRJ and WEG jointly conceived and coordinated the study. All authors reviewed and approved of the final manuscript.

\section{Acknowledgements}

This study was funded in part by a grant from the Susan G. Komen Breast Cancer Foundation (BCTR0600484), the Breast SPORE (CA089010-09) and the U54 (CA118948).

\section{Author details}

${ }^{1}$ Department of Medicine, Division of Endocrinology, University of Alabama at Birmingham, Birmingham, AL 35294, USA. ${ }^{2}$ Department of Obstetrics and Gynecology, University of Alabama at Birmingham, Birmingham, AL 35294, USA. ${ }^{3}$ Department of Chemical Engineering, Tuskegee University, Tuskegee, AL 36088, USA. ${ }^{4}$ Department of Pathology, University of Alabama at Birmingham, Zeigler Research Building, 703 South 19th Street, ZRB 408, Birmingham, AL 35294, USA. 5 Department of Pharmacology and Toxicology, University of Alabama at Birmingham, Birmingham, AL 35294, USA.

Received: 1 September 2011 Accepted: 25 April 2012

Published: 22 May 2012

\section{References}

1. Society AC: Breast cancer facts and figures: 2009-2010. Atlanta: American Cancer Society, Inc.; 2009.

2. Society AC: Cancer Fact and Figures for African Americans 2011-2012. Atlanta: American Cancer Society; 2011.

3. Newman LA: Breast cancer in African-American women. Oncologist 2005 10(1):1-14.

4. Chen W, Correa P, Kurman RJ, Wu XC, Eley JW, Austin D, Muss H, Hunter CP, Redmond C, Sobhan M, et al: Histological characteristics of breast carcinoma in blacks and whites. Canc Epidemiol Biomarkers Prev 1994, 3(2):127-135.

5. Fedewa SA, Edge SB, Stewart AK, Halpern MT, Marlow NM, Ward EM: Race and ethnicity are associated with delays in breast cancer treatment (2003-2006). J Health Care Poor Underserved 2011, 22(1):128-141.

6. Fedewa SA, Ward EM, Stewart AK, Edge SB: Delays in adjuvant chemotherapy treatment among patients with breast cancer are more likely in African American and Hispanic populations: a national cohort study 2004-2006. J Clin Oncol 2010, 28(27):4135-4141.

7. Freedman RA, Virgo KS, He Y, Pavluck AL, Winer EP, Ward EM, Keating NL: The association of race/ethnicity, insurance status, and socioeconomic factors with breast cancer care. Cancer 2011, 117(1):180-189. 
8. Gullate M: The influence of spirituality and religiosity on breast cancer screening delay in African American women: application of the Theory of Reasoned Action and Planned Behavior (TRA/TPB). ABNF J 2006, 17(2):89-94.

9. Wang J, John EM, Horn-Ross PL, Ingles SA: Dietary fat, cooking fat, and breast cancer risk in a multiethnic population. Nutr Cancer 2008, 60 (4):492-504.

10. Newman LA, Griffith KA, Jatoi I, Simon MS, Crowe JP, Colditz GA Meta-analysis of survival in African American and white American patients with breast cancer: ethnicity compared with socioeconomic status. J Clin Oncol 2006, 24(9):1342-1349.

11. Newman LA, Mason J, Cote D, Vin Y, Carolin K, Bouwman D, Colditz GA: African-American ethnicity, socioeconomic status, and breast cancer survival: a meta-analysis of 14 studies involving over 10,000 AfricanAmerican and 40,000 White American patients with carcinoma of the breast. Cancer 2002, 94(11):2844-2854.

12. Jatoi I, Becher $\mathrm{H}$, Leake CR: Widening disparity in survival between white and African-American patients with breast carcinoma treated in the U.S. Department of Defense Healthcare system. Cancer 2003, 98 (5):894-899

13. Wojcik BE, Spinks MK, Optenberg SA: Breast carcinoma survival analysis for African American and white women in an equal-access health care system. Cancer 1998, 82(7):1310-1318.

14. Albain KS, Unger JM, Crowley JJ, Coltman CA Jr, Hershman DL: Racial disparities in cancer survival among randomized clinical trials patients of the Southwest Oncology Group. J Natl Cancer Inst 2009, 101(14):984-992.

15. Carey LA, Perou CM, Livasy CA, Dressler LG, Cowan D, Conway K, Karaca G, Troester MA, Tse CK, Edmiston S, et al: Race, breast cancer subtypes, and survival in the Carolina Breast Cancer Study. JAMA 2006, 295(21):2492-2502

16. Nielsen TO, Hsu FD, Jensen K, Cheang M, Karaca G, Hu Z, HernandezBoussard T, Livasy C, Cowan D, Dressler L, et al: Immunohistochemical and clinical characterization of the basal-like subtype of invasive breast carcinoma. Clin Cancer Res 2004, 10(16):5367-5374.

17. Amend K, Hicks D, Ambrosone CB: Breast cancer in African-American women: differences in tumor biology from European-American women. Cancer Res 2006, 66(17):8327-8330.

18. Ihemelandu CU, Leffall LD Jr, Dewitty RL, Naab TJ, Mezghebe HM, Makambi KH, Adams-Campbell L, Frederick WA: Molecular breast cancer subtypes in premenopausal African-American women, tumor biologic factors and clinical outcome. Ann Surg Oncol 2007, 14(10):2994-3003.

19. Porter PL, Garcia R, Moe R, Corwin DJ, Gown AM: C-erbB-2 oncogene protein in in situ and invasive lobular breast neoplasia. Cancer 1991 68(2):331-334

20. Porter PL, Lund MJ, Lin MG, Yuan X, Liff JM, Flagg EW, Coates RJ, Eley JW Racial differences in the expression of cell cycle-regulatory proteins in breast carcinoma. Cancer 2004, 100(12):2533-2542.

21. Rakha EA, Abd El Rehim D, Pinder SE, Lewis SA, Ellis IO: E-cadherin expression in invasive non-lobular carcinoma of the breast and its prognostic significance. Histopathology 2005, 46(6):685-693.

22. Lund MJ, Trivers KF, Porter PL, Coates RJ, Leyland-Jones B, Brawley OW Flagg EW, O'Regan RM, Gabram SG, Eley JW: Race and triple negative threats to breast cancer survival: a population-based study in Atlanta, GA. Breast Cancer Res Treat 2009, 113(2):357-370

23. Hall MJ, Reid JE, Burbidge LA, Pruss D, Deffenbaugh AM, Frye C, Wenstrup RJ, Ward BE, Scholl TA, Noll WW: BRCA1 and BRCA2 mutations in women of different ethnicities undergoing testing for hereditary breast-ovarian cancer. Cancer 2009, 115(10):2222-2233.

24. Field LA, Love B, Deyarmin B, Hooke JA: Shriver CD. Ellsworth RE: Identification of differentially expressed genes in breast tumors from African American compared with Caucasian women. Cancer; 2011.

25. Hammond ME, Hayes DF, Dowsett M, Allred DC, Hagerty KL, Badve S, Fitzgibbons PL, Francis G, Goldstein NS, Hayes M, et al: American Society of Clinical Oncology/College of American Pathologists guideline recommendations for immunohistochemical testing of estrogen and progesterone receptors in breast cancer. Arch Pathol Lab Med 2010, 134(6):907-922.

26. Vance GH, Barry TS, Bloom KJ, Fitzgibbons PL, Hicks DG, Jenkins RB, Persons DL, Tubbs RR, Hammond ME: Genetic heterogeneity in HER2 testing in breast cancer: panel summary and guidelines. Arch Pathol Lab Med 2009, 133(4):611-612.
27. Steg A, Vickers SM, Eloubeidi M, Wang W, Eltoum IA, Grizzle WE, Saif MW Lobuglio AF, Frost AR, Johnson MR: Hedgehog pathway expression in heterogeneous pancreatic adenocarcinoma: implications for the molecular analysis of clinically available biopsies. Diagn Mol Pathol 2007, 16(4):229-237

28. Blanquicett C, Johnson MR, Heslin M, Diasio RB: Housekeeping gene variability in normal and carcinomatous colorectal and liver tissues: applications in pharmacogenomic gene expression studies. Anal Biochem 2002, 303(2):209-214

29. Steg A, Wang W, Blanquicett C, Grunda JM, Eltoum IA, Wang K, Buchsbaum DJ, Vickers SM, Russo S, Diasio RB, et al: Multiple gene expression analyses in paraffin-embedded tissues by TaqMan low-density array: Application to hedgehog and Wnt pathway analysis in ovarian endometrioid adenocarcinoma. J Mol Diagn 2006, 8(1):76-83.

30. Fisher RA: Statistical Methods for Research Workers.: Oliver and Boyd; 1954.

31. Hallander M, Wolfe D: Nonparametric Statistical Methods. 1999, (2nd).

32. Bair E, Tibshirani R: Semi-supervised methods to predict patient survival from gene expression data. PLoS Biol 2004, 2(4):E108.

33. Mullighan CG, Su X, Zhang J, Radtke I, Phillips LA, Miller CB, Ma J, Liu W, Cheng C, Schulman BA, et al: Deletion of IKZF1 and prognosis in acute lymphoblastic leukemia. N Engl J Med 2009, 360(5):470-480.

34. Massey F: The Kolmogorov-Smirnov test for goodness of fit. J Am Stat Assoc 1951, 46(253):68-78.

35. Johnson R, Wichern D: Applied Multivariate Statistical Analysis.: Prentice-Hall, Inc; 1982.

36. Farragher SM, Tanney A, Kennedy RD, Paul Harkin D: RNA expression analysis from formalin fixed paraffin embedded tissues. Histochem Cell Biol 2008, 130(3):435-445.

37. Klopfleisch R, Weiss AT, Gruber AD: Excavation of a buried treasure-DNA, mRNA, miRNA and protein analysis in formalin fixed, paraffin embedded tissues. Histol Histopathol 2011, 26(6):797-810.

38. Grunda JM, Nabors LB, Palmer CA, Chhieng DC, Steg A, Mikkelsen T, Diasio RB, Zhang $K$, Allison D, Grizzle WE, et al: Increased expression of thymidylate synthetase (TS), ubiquitin specific protease 10 (USP10) and survivin is associated with poor survival in glioblastoma multiforme (GBM). J Neurooncol 2006, 80(3):261-274.

39. Porter PL, Malone KE, Heagerty PJ, Alexander GM, Gatti LA, Firpo EJ, Daling JR, Roberts JM: Expression of cell-cycle regulators p27Kip1 and cyclin E, alone and in combination, correlate with survival in young breast cancer patients. Nat Med 1997, 3(2):222-225.

40. Catzavelos C, Bhattacharya N, Ung YC, Wilson JA, Roncari L, Sandhu C, Shaw P, Yeger H, Morava-Protzner I, Kapusta L, et al: Decreased levels of the cell-cycle inhibitor p27Kip1 protein: prognostic implications in primary breast cancer. Nat Med 1997, 3(2):227-230

41. Gorgoulis VG, Koutroumbi EN, Kotsinas A, Zacharatos P, Markopoulos C, Giannikos L, Kyriakou V, Voulgaris Z, Gogas I, Kittas C: Alterations of p16pRb pathway and chromosome locus 9p21-22 in sporadic invasive breast carcinomas. Mol Med 1998, 4(12):807-822.

42. Han S, Ahn SH, Park K, Bae BN, Kim KH, Kim HJ, Kim YD, Kim HY: P16INK4a protein expression is associated with poor survival of the breast cancer patients after CMF chemotherapy. Breast Cancer Res Treat 2001 , 70(3):205-212

43. Milde-Langosch K, Bamberger AM, Rieck G, Kelp B, Loning T: Overexpression of the p16 cell cycle inhibitor in breast cancer is associated with a more malignant phenotype. Breast Cancer Res Treat 2001, 67(1):61-70

44. Steeg PS, Zhou Q: Cyclins and breast cancer. Breast Cancer Res Treat 1998, 52(1-3):17-28.

45. Satyanarayana A, Kaldis P: Mammalian cell-cycle regulation: several Cdks, numerous cyclins and diverse compensatory mechanisms. Oncogene 2009, 28(33):2925-2939.

46. Michalides $R$, Hageman $P$, van Tinteren $H$, Houben L, Wientjens $E$, Klompmaker R, Peterse J: A clinicopathological study on overexpression of cyclin D1 and of p53 in a series of 248 patients with operable breast cancer. Br J Cancer 1996, 73(6):728-734.

47. Christov K, Ikui A, Shilkaitis A, Green A, Yao R, You M, Grubbs C, Steele V, Lubet $R$, Weinstein IB: Cell proliferation, apoptosis, and expression of cyclin D1 and cyclin E as potential biomarkers in tamoxifen-treated mammary tumors. Breast Cancer Res Treat 2003, 77(3):253-264 
48. Nielsen NH, Loden M, Cajander J, Emdin SO, Landberg G: G1-S transition defects occur in most breast cancers and predict outcome. Breast Cancer Res Treat 1999, 56(2):105-112.

49. Dublin EA, Patel NK, Gillett CE, Smith P, Peters G, Barnes DM: Retinoblastoma and 16 proteins in mammary carcinoma: their relationship to cyclin D1 and histopathological parameters. Int J Cancer 1998, 79(1):71-75.

50. Chlebowski RT, Chen Z, Anderson GL, Rohan T, Aragaki A, Lane D, Dolan NC, Paskett ED, McTiernan A, Hubbell FA, et al: Ethnicity and breast cancer: factors influencing differences in incidence and outcome. J Nat/ Cancer Inst 2005, 97(6):439-448.

51. Joslyn SA: Hormone receptors in breast cancer: racial differences in distribution and survival. Breast Cancer Res Treat 2002, 73(1):45-59.

52. Elledge RM, Clark GM, Chamness GC, Osborne CK: Tumor biologic factors and breast cancer prognosis among white, Hispanic, and black women in the United States. J Natl Cancer Inst 1994, 86(9):705-712.

53. Chu KC, Anderson WF, Fritz A, Ries LA, Brawley OW: Frequency distributions of breast cancer characteristics classified by estrogen receptor and progesterone receptor status for eight racial/ethnic groups. Cancer 2001, 92(1):37-45.

54. Callahan R, Hurvitz S: Human epidermal growth factor receptor-2-positive breast cancer: Current management of early, advanced, and recurrent disease. Curr Opin Obstet Gynecol 2011, 23(1):37-43.

55. Campiglio M, Bufalino R, Sandri M, Ferri E, Aiello RA, De Matteis A, Mottolese M, De Placido S, Querzoli P, Jirillo A, et al: Increased overall survival independent of RECIST response in metastatic breast cancer patients continuing trastuzumab treatment: evidence from a retrospective study. Breast Cancer Res Treat 2011, 128(1):147-154.

56. Burris HA: Trastuzumab emtansine: a novel antibody-drug conjugate for HER2-positive breast cancer. Expert Opin Biol Ther 2011, 11(6):807-819.

57. Tozlu S, Girault I, Vacher S, Vendrell J, Andrieu C, Spyratos F, Cohen P, Lidereau R, Bieche I: Identification of novel genes that co-cluster with estrogen receptor alpha in breast tumor biopsy specimens, using a large-scale real-time reverse transcription-PCR approach. Endocr Relat Cancer 2006, 13(4):1109-1120.

58. Wilson BJ, Giguere V: Meta-analysis of human cancer microarrays reveals GATA3 is integral to the estrogen receptor alpha pathway. Mol Cancer 2008, 7:49.

59. Kallel-Bayoudh I, Hassen HB, Khabir A, Boujelbene N, Daoud J, Frikha M, Sallemi-Boudawara T, Aifa S, Rebai A: Bcl-2 expression and triple negative profile in breast carcinoma. Med Oncol 2010, 28(Suppl 1):S55-S61.

60. Spyratos F, Andrieu C, Vidaud D, Briffod M, Vidaud M, Lidereau R, Bieche I: CCND1 mRNA overexpression is highly related to estrogen receptor positivity but not to proliferative markers in primary breast cancer. Int $J$ Biol Markers 2000, 15(3):210-214.

61. Marconett CN, Sundar SN, Poindexter KM, Stueve TR, Bjeldanes LF, Firestone GL: Indole-3-carbinol triggers aryl hydrocarbon receptor-dependent estrogen receptor (ER)alpha protein degradation in breast cancer cells disrupting an ERalpha-GATA3 transcriptional cross-regulatory loop. Mol Biol Cell 2010, 21(7):1166-1177.

62. Mehra R, Varambally S, Ding L, Shen R, Sabel MS, Ghosh D, Chinnaiyan AM, Kleer CG: Identification of GATA3 as a breast cancer prognostic marker by global gene expression meta-analysis. Canc Res 2005, 65(24):11259-11264.

63. Rakha EA, Boyce RW, Abd El-Rehim D, Kurien T, Green AR, Paish EC, Robertson JF, Ellis IO: Expression of mucins (MUC1, MUC2, MUC3, MUC4, MUC5AC and MUC6) and their prognostic significance in human breast cancer. Mod Pathol 2005, 18(10):1295-1304.

64. Wei $X, X u H$, Kufe D: MUC1 oncoprotein stabilizes and activates estrogen receptor alpha. Mol Cell 2006, 21(2):295-305.

65. Napieralski R, Brunner N, Mengele K, Schmitt M: Emerging biomarkers in breast cancer care. Biomark Med 2010, 4(4):505-522.

66. Minisini AM, Fabbro D, Di Loreto C, Pestrin M, Russo S, Cardellino GG, Andreetta C, Damante G, Puglisi F: Markers of the uPA system and common prognostic factors in breast cancer. Am J Clin Pathol 2007, 128(1):112-117.

67. Smith LH, Coats SR, Qin H, Petrie MS, Covington JW, Su M, Eren M, Vaughan DE: Differential and opposing regulation of PAl-1 promoter activity by estrogen receptor alpha and estrogen receptor beta in endothelial cells. Circ Res 2004, 95(3):269-275.

68. Cimino D, Fuso L, Sfiligoi C, Biglia N, Ponzone R, Maggiorotto F, Russo G, Cicatiello L, Weisz A, Taverna D, et al: Identification of new genes associated with breast cancer progression by gene expression analysis of predefined sets of neoplastic tissues. Int J Canc J Int du cancer 2008, 123(6):1327-1338.

69. Yamamura J, Miyoshi Y, Tamaki Y, Taguchi T, Iwao K, Monden M, Kato K, Noguchi S: mRNA expression level of estrogen-inducible gene, alpha 1antichymotrypsin, is a predictor of early tumor recurrence in patients with invasive breast cancers. Cancer Sci 2004, 95(11):887-892.

70. Bouras T, Southey MC, Chang AC, Reddel RR, Willhite D, Glynne R, Henderson MA, Armes JE, Venter DJ: Stanniocalcin 2 is an estrogenresponsive gene coexpressed with the estrogen receptor in human breast cancer. Canc Res 2002, 62(5):1289-1295.

71. Michels KM, Lee WH, Seltzer A, Saavedra JM, Bondy CA: Up-regulation of pituitary [125I]insulin-like growth factor-I (IGF-I) binding and IGF binding protein-2 and IGF-I gene expression by estrogen. Endocrinology 1993, 132(1):23-29.

72. Rooman RP, De Beeck LO, Martin M, Van Doorn J, Mohan S, Du Caju MV: IGF-I, IGF-II, 'free' IGF-I and IGF-binding proteins-2 to -6 during highdose oestrogen treatment in constitutionally tall girls. Eur J Endocrinol 2002, 146(6):823-829.

73. Wilson CL, Sims AH, Howell A, Miller CJ, Clarke RB: Effects of oestrogen on gene expression in epithelium and stroma of normal human breast tissue. Endocrine-related cancer 2006, 13(2):617-628.

74. Graham JD, Roman SD, McGowan E, Sutherland RL, Clarke CL: Preferential stimulation of human progesterone receptor $B$ expression by estrogen in T47D human breast cancer cells. J Biol Chem 1995, 270(51):30693-30700.

75. Kastner P, Krust A, Turcotte B, Stropp U, Tora L, Gronemeyer H, Chambon P: Two distinct estrogen-regulated promoters generate transcripts encoding the two functionally different human progesterone receptor forms A and B. Embo J 1990, 9(5):1603-1614.

76. Saucedo R, Basurto L, Zarate A, Martinez C, Hernandez M, Galvan R: Effect of estrogen therapy on insulin resistance and plasminogen activator inhibitor type 1 concentrations in postmenopausal women. Gynecol Obstet Invest 2007, 64(2):61-64.

77. Adams DJ, Hajj H, Edwards DP, Bjercke RJ, McGuire WL: Detection of a Mr 24,000 estrogen-regulated protein in human breast cancer by monoclonal antibodies. Can Res 1983, 43(9):4297-4301.

78. Andersen J, Skovbon H, Poulsen HS: Immunocytochemical determination of the estrogen-regulated protein $\mathrm{Mr} 24,000$ in primary breast cancer and response to endocrine therapy. Eur J Cancer Clin Oncol 1989, 25(4):641-643.

79. Ciocca DR, Adams DJ, Edwards DP, Bjercke RJ, McGuire WL: Estrogeninduced $24 \mathrm{~K}$ protein in MCF-7 breast cancer cells is localized in granules. Breast Canc Res Treat 1984, 4(4):261-268.

80. Kroll J, Briand P: Estrogen-dependent release of serum proteins from MCF-7 breast carcinoma cells in vitro. Anticancer Res 1988, 8(1):89-91.

81. Massot O, Baskevitch PP, Capony F, Garcia M, Rochefort H: Estradiol increases the production of alpha 1-antichymotrypsin in MCF7 and T47D human breast cancer cell lines. Mol Cell Endocrinol 1985, 42(3):207-214.

82. Dawson SJ, Makretsov N, Blows FM, Driver KE, Provenzano E, Le Quesne J, Baglietto L, Severi G, Giles GG, McLean CA, et al: BCL2 in breast cancer: a favourable prognostic marker across molecular subtypes and independent of adjuvant therapy received. Brit J Canc 2010, 103(5):668-675.

83. Nadler Y, Camp RL, Giltnane JM, Moeder C, Rimm DL, Kluger HM, Kluger Y: Expression patterns and prognostic value of Bag-1 and Bcl-2 in breast cancer. Breast Canc Res 2008, 10(2):R35.

84. Gillett C, Smith P, Gregory W, Richards M, Millis R, Peters G, Barnes D: Cyclin D1 and prognosis in human breast cancer. Int J Cancer 1996, 69(2):92-99.

85. Oh DS, Troester MA, Usary J, Hu Z, He X, Fan C, Wu J, Carey LA, Perou CM: Estrogen-regulated genes predict survival in hormone receptor-positive breast cancers. J Clin Oncol: Official Journal of the American Society of Clinical Oncology 2006, 24(11):1656-1664.

86. Yoon NK, Maresh EL, Shen D, Elshimali Y, Apple S, Horvath S, Mah V, Bose S, Chia D, Chang HR, et al: Higher levels of GATA3 predict better survival in women with breast cancer. Hum Pathol 2010, 41(12):1794-1801.

87. Karczewska A, Nawrocki S, Breborowicz D, Filas V, Mackiewicz A: Expression of interleukin-6, interleukin-6 receptor, and glycoprotein 130 correlates with good prognoses for patients with breast carcinoma. Cancer 2000, 88(9):2061-2071

88. Tjensvoll K, Oltedal S, Farmen RK, Shammas FV, Heikkila R, Kvaloy JT, Gilje B, Smaaland $R$, Nordgard $O$ : Disseminated tumor cells in bone marrow assessed by TWIST1, cytokeratin 19, and mammaglobin A mRNA predict 
clinical outcome in operable breast cancer patients. Clin Breast Cancer 2010, 10(5):378-384.

89. van der Vegt B, de Roos MA, Peterse JL, Patriarca C, Hilkens J, de Bock GH, Wesseling J: The expression pattern of MUC1 (EMA) is related to tumour characteristics and clinical outcome of invasive ductal breast carcinoma. Histopathology 2007, 51(3):322-335.

90. Clark GM, McGuire WL: Progesterone receptors and human breast cancer. Breast Canc Res Treat 1983, 3(2):157-163.

91. Esseghir S, Kennedy A, Seedhar P, Nerurkar A, Poulsom R, Reis-Filho JS, Isacke CM: Identification of NTN4, TRA1, and STC2 as prognostic markers in breast cancer in a screen for signal sequence encoding proteins. Clin Canc Res: an official Journal of the American Association for Cancer Research 2007, 13(11):3164-3173.

92. Schippinger W, Regitnig P, Dandachi N, Wernecke KD, Bauernhofer T, Samonigg H, Moinfar F: Evaluation of the prognostic significance of androgen receptor expression in metastatic breast cancer. Virchows Arch 2006, 449(1):24-30.

93. Anderson JM, Van Itallie CM: Physiology and function of the tight junction. Cold Spring Harb Perspect Biol 2009, 1(2):a002584.

94. Gupta IR, Ryan AK: Claudins: unlocking the code to tight junction function during embryogenesis and in disease. Clin Genet 2010, 77(4):314-325.

95. Morin PJ: Claudin proteins in human cancer: promising new targets for diagnosis and therapy. Cancer Res 2005, 65(21):9603-9606.

96. Blackman B, Russell T, Nordeen SK, Medina D, Neville MC: Claudin 7 expression and localization in the normal murine mammary gland and murine mammary tumors. Breast Cancer Res 2005, 7(2):R248-R255.

97. Kominsky SL, Argani P, Korz D, Evron E, Raman V, Garrett E, Rein A, Sauter G, Kallioniemi OP, Sukumar S: Loss of the tight junction protein claudin-7 correlates with histological grade in both ductal carcinoma in situ and invasive ductal carcinoma of the breast. Oncogene 2003, 22(13):2021-2033.

98. Sauer T, Pedersen MK, Ebeltoft K, Naess O: Reduced expression of Claudin7 in fine needle aspirates from breast carcinomas correlate with grading and metastatic disease. Cytopathology 2005, 16(4):193-198.

99. Lahoz A, Hall A: DLC1: a significant GAP in the cancer genome. Genes Dev 2008, 22(13):1724-1730.

100. Sekimata M, Kabuyama Y, Emori Y, Homma Y: Morphological changes and detachment of adherent cells induced by p122, a GTPase-activating protein for Rho. J Biol Chem 1999, 274(25):17757-17762.

101. Zhou X, Thorgeirsson SS, Popescu NC: Restoration of DLC-1 gene expression induces apoptosis and inhibits both cell growth and tumorigenicity in human hepatocellular carcinoma cells. Oncogene 2004, 23(6):1308-1313.

102. Durkin ME, Yuan BZ, Thorgeirsson SS, Popescu NC: Gene structure, tissue expression, and linkage mapping of the mouse DLC-1 gene (Arhgap7). Gene 2002, 288(1-2):119-127.

103. Yuan BZ, Zhou X, Durkin ME, Zimonjic DB, Gumundsdottir K, Eyfjord JE, Thorgeirsson SS, Popescu NC: DLC-1 gene inhibits human breast cancer cell growth and in vivo tumorigenicity. Oncogene 2003, 22(3):445-450.

104. Yuan BZ, Miller MJ, Keck CL, Zimonjic DB, Thorgeirsson SS, Popescu NC: Cloning, characterization, and chromosomal localization of a gene frequently deleted in human liver cancer (DLC-1) homologous to rat RhoGAP. Cancer Res 1998, 58(10):2196-2199.

105. Plaumann M, Seitz S, Frege R, Estevez-Schwarz L, Scherneck S: Analysis of DLC-1 expression in human breast cancer. J Cancer Res Clin Oncol 2003, 129(6):349-354.

106. Holeiter G, Heering J, Erlmann P, Schmid S, Jahne R, Olayioye MA: Deleted in liver cancer 1 controls cell migration through a Dia1-dependent signaling pathway. Cancer Res 2008, 68(21):8743-8751.

\section{doi:10.1186/1756-0500-5-248}

Cite this article as: Grunda et al: Differential expression of breast cancer-associated genes between stage- and age-matched tumor specimens from African- and Caucasian-American Women diagnosed with breast cancer. BMC Research Notes 2012 5:248.

\section{Submit your next manuscript to BioMed Central and take full advantage of:}

- Convenient online submission

- Thorough peer review

- No space constraints or color figure charges

- Immediate publication on acceptance

- Inclusion in PubMed, CAS, Scopus and Google Scholar

- Research which is freely available for redistribution

Submit your manuscript at www.biomedcentral.com/submit
() Biomed Central 